\title{
Redo Aortic and Mitral Valve Replacement using St. Jude Medical Mechanical Prosthesis in a Patient with Degenerated Mitral Bioprosthesis and Severe Aortic Regurgitation: A Video Presentation
}

\author{
Ujjwal K. Chowdhury,® Lakshmi Kumari Sankhyan ${ }^{1} \quad$ Sukhjeet Singh ${ }^{1} \quad$ Niwin George ${ }^{1}$ Sandeep Sharan ${ }^{1}$ \\ Poonam Malhotra Kapoor ${ }^{1}$ Parag Gharde ${ }^{1} \quad$ Sanjoy Sengupta ${ }^{1} \quad$ Sushamagayatri B ${ }^{1}$ \\ ${ }^{1}$ Cardio-Thoracic Sciences Centre, All India Institute of Medical \\ Sciences, New Delhi, India

\begin{abstract}
Address for correspondence Dr. Ujjwal Kumar Chowdhury, M.Ch, Diplomate NB, Professor, Department of Cardiothoracic and Vascular Surgery, All India Institute of Medical Sciences, New Delhi-110029, India (e-mail: ujjwalchow@rediffmail.com, ujjwalchowdhury@gmail.com).
\end{abstract}

J Card Crit Care 2021;5:151-153.

\author{
Abstract \\ Keywords \\ - mechanical prostheses \\ - patient with \\ degenerated mitral \\ bioprosthesis \\ - redo aortic and mitral \\ valve replacement \\ - severe aortic \\ regurgitation
}

The American College of Cardiology/American Heart Association practice guidelines suggest bioprosthetic aortic and mitral valve replacement is a reasonable option for patients older than 65 years and for selected patients younger than 65 years according to patients' preference. However, routine use of bioprosthetic valves in younger patients remains controversial. Patients prevalence to avoid anticoagulation, decreasing operative risks for valve reoperations, and the availability of catheter valve-in-valve techniques have created a need to reexamine bioprosthetic valve durability, particularly in young patients undergoing valve replacements

\section{Introduction}

The American College of Cardiology/American Heart Association practice guidelines suggest bioprosthetic aortic and mitral valve replacement as a reasonable option for patients older than 65 years and for selected patients younger than 65 years according to patients' preference., ${ }^{1,2}$ However, routine use of bioprosthetic valves in younger patients remains controversial. Patients prevalence to avoid anticoagulation, decreasing operative risks for valve reoperations, and the availability of catheter valve-in-valve techniques have created a need to reexamine bioprosthetic valve durability, particularly in young patients undergoing valve replacements. ${ }^{3-5}$

In developing countries, the severity and rapid progression of valvular disease to rheumatic heart disease in pediatric age group and in young adults poses a challenging problem. ${ }^{6}$
The severity of anatomic changes in young patients with rheumatic heart disease precludes reparative procedures. ${ }^{4-12}$

Younger patients with rheumatic heart disease undergoing mechanical mitral valve replacement require life-long anticoagulation and are at risk of bleeding and thromboembolic complications. ${ }^{4-12}$

The reported incidence of survival following mechanical mitral valve replacement in the published literature at 10 , 20 , and 30 years is 61 to $75 \%, 36.5$ to $39 \%$ and $22.6 \%$, respectively. ${ }^{4-9,12}$ Although tissue heart valves are an established choice in older age groups, there is a reluctance in using tissue valves in younger age groups because of higher reoperation rates which are inversely proportional to the age of the patients., ${ }^{24-12}$

The Carpentier-Edwards Perimount pericardial bioprosthetic (Edwards Lifesciences, Irvine, CA) is a second published online

August 16, 2021
DOI https://doi.org/

$10.1055 / \mathrm{s}-0041-1723625$

ISSN 2457-0206.
(C) 2021. Official Publication of The Simulation Society (TSS), accredited by International Society of Cardiovascular Ultrasound (ISCU).

This is an open access article published by Thieme under the terms of the Creative Commons Attribution-NonDerivative-NonCommercial-License, permitting copying and reproduction so long as the original work is given appropriate credit. Contents may not be used for commercial purposes, or adapted, remixed, transformed or built upon. (https://creativecommons.org/licenses/by-nc-nd/4.0/)

Thieme Medical and Scientific Publishers Pvt. Ltd., A-12, 2nd Floor, Sector 2, Noida-201301 UP, India 
generation trileaflet bioprosthetic valve consisting of bovine pericardial leaflets mounted on a flexible frame. The design of the valve was aimed at improving on the limited durability of porcine bioprostheses and poor performance of the first-generation pericardial valves., ${ }^{4,53-16}$

Studies on long-term new-generation Carpentier-Edwards pericardial bioprostheses (Perimount) have documented excellent hemodynamic profile and a low incidence of structural deterioration with freedom from reoperation being $89.5 \% \pm 5 \%$ at 15 years. $^{3-5,13-16}$

With this background, a group of 132 patients less than 40 years of age underwent mitral valve replacement using Perimount pericardial bioprosthesis model 6900-mitral (Edwards life sciences, Irvine, CA, US) at the All India Institute of Medical Sciences, New Delhi, India. The actuarial survival and actuarial event-free survival at 204 months was $96.9 \%$ ( $\pm 0.01 \%)$ and $93.4 \%$ ( $\pm 0.03 \%)$, respectively. At the time of reporting in 2017, 6 (4.7\%) patients underwent redo mitral valve replacement for severe bioprosthetic degeneration with stiffening and calcification. ${ }^{3}$

We report herein our seventh patient from this series who underwent mitral valve replacement 13 years back using a $31 \mathrm{~mm}$ Carpentier-Edwards pericardial perimount prosthesis. He underwent redo aortic and mitral valve replacement using St. Jude Medical mechanical prosthesis. The indication for reoperation was severe bioprosthetic degeneration with severe aortic regurgitation. He was weaned off cardiopulmonary bypass on dopamine $5 \mu \mathrm{g} / \mathrm{kg} / \mathrm{min}$, dobutamine $10 \mu \mathrm{g} / \mathrm{kg} / \mathrm{min}$, and adrenaline $0.01 \mu \mathrm{g} / \mathrm{kg} / \mathrm{min}$ with stable hemodynamics.

\section{Surgical Techniques}

Following systemic heparinization, elective right femoral arteriovenous cannulation is done using long femoral arterial and venous cannulae (Edwards Lifesciences LLC, One Edwards Way, Irvine, CA, USA).

Under cardiopulmonary bypass, secondary median sternotomy was performed with the heart decompressed on bypass. The pericardium overlying the aorta, right ventricular outflow tract, and superior vena cava was dissected.

An 18-Fr sump suction vent was placed over the main pulmonary artery for further decompression of the heart to facilitate dissection. The superior caval vein was dissected and cannulated directly using an angled metal tipped venous cannula and drained directly into the oxygenator. The intrapericardial inferior caval vein was dissected and looped for later occlusion.

The right pleural cavity was widely opened. Due to dense adhesions overlying the right and left atrium, the pericardium overlying body of the right atrium was not dissected. The patient was planned for transeptal approach of mitral re-replacement.

The aorta was cross-clamped using an atraumatic aortic vascular clamp. An oblique horseshoe-shaped aortotomy was done starting $2 \mathrm{~cm}$ above the right coronary sinus and ending $1 \mathrm{~cm}$ above the mid-point of noncoronary sinus. Myocardial protection was achieved by integrated myocardial protection using direct osteal St. Thomas (II) based cold blood cardioplegia (4:1) and topical cardiac cooling using ice cold saline. Successive doses of cardioplegia were repeated every 30 minutes.

After snugging the inferior caval vein, the pericardium overlying the right atrium was directly incised in between stay sutures. The interatrial septum was incised and opened in between stay sutures.

Two stay sutures of 2-0 Ethibond (Johnson and Johnson Ltd., Ethicon, LLC, San Lorenzo, USA) were placed over the prosthetic mitral annulus to facilitate later explantation of the mitral prosthesis.

An incision was made on the mitral prosthetic ring using a No.11 scalpel blade. The prosthetic valve was detached from the anterior atrioventricular groove by a combined sharp and blunt dissection ( - Figs. 1 a-c).

A small right angle forceps was insinuated within the opening to facilitate explantation of the mitral prosthesis. The prosthetic valve was explanted by incising the prosthetic fibrous capsule on both atrial and ventricular surfaces. Extreme precautions were taken not to cause type I atrioventricular groove rupture. Precautions were also taken not the dislodge the thrombus contained within the prosthetic mitral valve. The posterior chordal apparatus was retained. The ventricular cavity is irrigated using cold normal saline.

Re-replacement of the mitral valve was done using a $29 \mathrm{~mm}$ St. Jude Medical mechanical prosthesis (St. Jude Medical; St
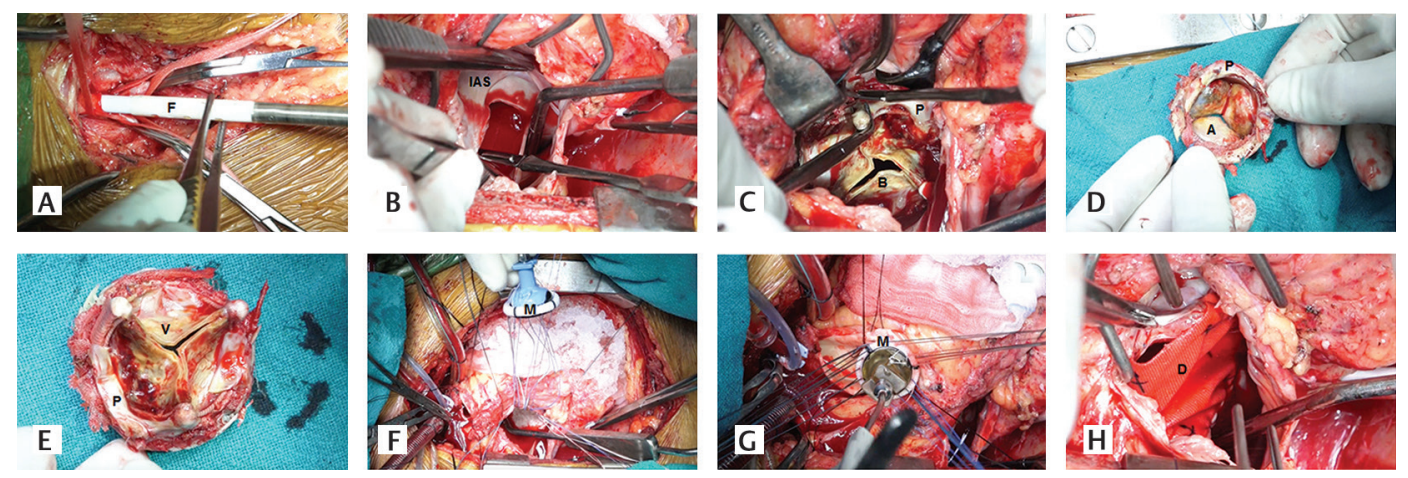

Fig. 1 (A-H) Step-by-step demonstration of explanation of the mitral bioprosthesis and implantation of a 29 mm St. Jude Mechanical mitral prosthesis via transseptal approach (A-atrial surface of degenerated bioprosthesis, B-degenerated bioprosthesis, D-Dacron polyester patch, F- femoral arterial cannula, I-interatrial septum, M-St. Jude Medical mechanical mitral prosthesis, P-prosthetic sewing, V-ventricular surface of degenerative bioprosthesis). 
Jude Medical; St. Paul, MN, USA) and interrupted 2-0 Ticron mattress suture ( - Figs. $\mathbf{1}$ d-h).

Three stay sutures of 2-0 atraumatic silk were placed on third aortic commissures. The incompetent, diseased aortic valve was excised and replaced using a No.21 St. Jude Medical mechanical aortic prosthesis and interrupted using a nonpledgeted 2-0 Ticron suture (M/s Covidien Domingo, Dominican Republic, USA).

The aortotomy was closed in two layers using 4-0 polypropylene suture: horizontal mattress and over and over continuous. The surgically created atrial septal defect was reconstructed using a Dacron polyester patch (Bard Savage filamentous knitted polyester fabric, Bard Peripheral Vascular Inc., Tempe, AZ, USA) ( - Fig. 1 h). The right atrium was closed in two layers using 2-0 polypropylene suture. The cardiac chambers were covered using a patch of bovine pericardium (Video 1).

\section{Video 1}

Online content including video sequences viewable at: https://www.thieme-connect.com/products/ejournals/ html/10.1055/s-0041-1723625.

\section{Results}

The patient had an uneventful postoperative recovery. At 14 months follow-up, he is in New York Heart Association functional class I with left ventricular ejection fraction 0.60 , normal aortic and mitral prosthetic valve function, and/or oral anticoagulation with warfarin.

\section{Conclusions}

Elective institution of cardiopulmonary bypass through femoro-femoral arteriovenous cannulation prior to sternotomy prevents accidental injury to the cardiac chambers and great vessels during sternal entry. Pulmonary artery venting and cannulation of the superior vena cava further facilitates dissection of the cardiac chambers without causing injury. Placement of two stay sutures on the prosthetic annulus and intracapsular dissection greatly facilitates explantation without causing rupture of the atrioventricular groove.

\section{Funding}

The authors received no financial support for the research, authorship, and/or publication of this article.

\section{Conflicts of Interest}

The author (s) declared no potential conflicts of interest with respect to the research, authorship, and/or publication of the article.

\section{References}

1 Bonow RO, Carabello BA, Chatterjee K, et al; American College of Cardiology/American Heart Association Task Force on Practice Guidelines. 2008 focused update incorporated into the ACC/AHA 2006 guidelines for the management of patients with valvular heart disease: a report of the American College of Cardiology/American Heart Association Task Force on Practice Guidelines (Writing Committee to revise the 1998 guidelines for the management of patients with valvular heart disease). Endorsed by the Society of Cardiovascular Anesthesiologists, Society for Cardiovascular Angiography and Interventions, and Society of Thoracic Surgeons. J Am Coll Cardiol 2008;52(13):e1-e142

2 Rahimtoola SH. Choice of prosthetic heart valve for adult patients. J Am Coll Cardiol 2003;41(6):893-904

3 Chowdhury UK, Rizvi A, Narang R, et al. Mitral valve replacement using Carpentier-Edwards pericardial bioprosthesis in patients with rheumatic heart disease aged below 40 years: 17-year results. Heart Lung Circ 2018;27(7):864-871

4 Jamieson WRE, Allen P, Miyagishima RT, et al. The CarpentierEdwards standard porcine bioprosthesis. A first-generation tissue valve with excellent long-term clinical performance. J Thorac Cardiovasc Surg 1990;99(3):543-561

5 Jamieson WRE, Miyagishima RT, Munro AI, et al. The CarpentierEdwards supra-annular porcine bioprosthesis: clinical performance to 8 years of a new generation porcine bioprosthesis. J Card Surg 1991;6(4, Suppl):562-567

6 John S, Ravikumar E, Jairaj PS, Chowdhury U, Krishnaswami S. Valve replacement in the young patient with rheumatic heart disease. Review of a twenty-year experience. J Thorac Cardiovasc Surg 1990;99(4):631-638

7 Ikonomidis JS, Kratz JM, Crumbley AJ III, et al. Twenty-year experience with the St Jude Medical mechanical valve prosthesis. J Thorac Cardiovasc Surg 2003;126(6):2022-2031

8 Gödje OL, Fischlein T, Adelhard K, Nollert G, Klinner W, Reichart B. Thirty-year results of Starr-Edwards prostheses in the aortic and mitral position. Ann Thorac Surg 1997;63(3): 613-619

9 Cannegieter SC, Rosendaal FR, Briët E. Thromboembolic and bleeding complications in patients with mechanical heart valve prostheses. Circulation 1994;89(2):635-641

10 Chowdhury UK, Kumar AS, Airan B, et al. Mitral valve replacement with and without chordal preservation in a rheumatic population: serial echocardiographic assessment of left ventricular size and function. Ann Thorac Surg 2005;79(6): 1926-1933

11 Chowdhury UK, Venkataiya JKH, Patel CD, et al. Serial radionuclide angiographic assessment of left ventricular ejection fraction and regional wall motion after mitral valve replacement in patients with rheumatic disease. Am Heart J 2006;152(6):1201-1207

12 Chowdhury UK, Sharma P, Sankhyan LK, Hasijs S, Narang R, Manikalaivani. Thromboembolic and bleeding complications following St. Jude Medical Valve Replacement. Ann Short Reports 2018;1:1009

13 Gallo I, Nistal F, Arbe E, Artiñano E. Comparative study of primary tissue failure between porcine (Hancock and Carpentier-Edwards) and bovine pericardial (Ionescu-Shiley) bioprostheses in the aortic position at five- to nine-year follow-up. Am J Cardiol 1988;61(10):812-816

14 Poirer NC, Pelletier LC, Pellerin M, Carrier M. 15-year experience with the Carpentier-Edwards pericardial bioprosthesis. Ann Thorac Surg 1998;66(6, Suppl):S57-S61

15 Marchand MA, Aupart MR, Norton R, et al. Fifteen-year experience with the mitral Carpentier-Edwards PERIMOUNT pericardial bioprosthesis. Ann Thorac Surg 2001;71(5, Suppl): S236-S239

16 Neville PH, Aupart MR, Diemont FF, Sirinelli AL, Lemoine EM, Marchand MA. Carpentier-Edwards pericardial bioprosthesis in aortic or mitral position: a 12-year experience. Ann Thorac Surg 1998;66(6, Suppl):S143-S147 